\title{
Ribotyping, Biotyping and Capsular Typing of Haemophilus influenzae Strains Isolated from Patients in Campinas, Southeast Brazil
}

\author{
Marcelo Lancellotti ${ }^{1}$, Fernanda de Pace $^{1}$, Eliana Guedes Stehling ${ }^{1}$, Maria Cecília Barisson Villares ${ }^{2}$, Marcelo Brocchi ${ }^{1}$ and \\ Wanderley Dias da Silveira ${ }^{1}$ \\ ${ }^{1}$ Department of Microbiology and Immunology; Biology Institute, Campinas State University; ${ }^{2}$ Department of Clinical Pathology, Medical \\ School Hospital, Campinas State University, Campinas, SP, Brazil
}

\begin{abstract}
Forty-five Haemophilus influenzae strains isolated from patients were characterized based on biochemical characteristics. Their capsular types were determined by polymerase chain reaction (PCR); they were compared, using two molecular methods [ribotyping with a specific DNA probe amplified from the 16S rDNA region from $H$. influenzae and through restriction fragment length polymorphism (RLFP) of an amplified 16S DNA region]. The strains were better discriminated by the ribotyping technique that used the $16 \mathrm{~S}$ probe and by the combination of both techniques. Biotypes I and IV were the most common, followed by biotypes VI, VIII and III. Biotypes II and VII were not found. Most of the capsular samples were nontypable (89\%), with capsular types a and $b$ found in 2 and $9 \%$ of the samples, respectively. We concluded that there is a very close genetic identity among pathogenic and nonpathogenic strains.
\end{abstract}

Key-Words: Haemophilus influenzae, characterization, ribotyping, serotype, biotype.

Haemophilus influenzae, a commensal pleomorphic Gramnegative bacillus found in the human upper respiratory tract, has been associated with localized and invasive infections, such as bronchitis, otitis, pneumonia, meningitis, septicemia, and epiglottitis [1]. Systemic diseases are normally caused by Haemophilus influenzae serotype b (Hib) strains. The isolates obtained from infectious processes of the respiratory tract and from healthy individuals are usually unencapsulated and nontypable (NTHI) [2]. The current classification of this species is based on biotypes and capsular serotypes, which are subject to phenotypic variations and do not provide any clonal origin data [3]. Other typing methods, such as outer membrane protein analysis, lipopolysaccharide profiling, and multilocus enzyme electrophoresis, have been used to study the epidemiology and pathogenesis of $H$. influenzae infections [4]. Recently, $H$. influenzae strains have also been genomically characterized by determination of capsular types based on biomolecular techniques, including PCR-ribotyping [5], RAPD-PCR [6], PFGE [4], and PCR [7,8], all of which have revealed a great variety of patterns.

Forty-five $H$. influenzae isolates from different body fluids of patients attended at the Medical School Hospital of the Universidade Estadual de Campinas (UNICAMP), Brazil between 1997 and 1998 were studied, using a combination of two different ribotyping methods. First, RFLP was used to amplify and cut a specific $16 \mathrm{~S}$ rDNA region of $\mathrm{H}$. influenzae with restriction enzymes, and then a DNA probe of the 16S rDNA region was used to hybridize with the restricted genomic DNA, in order to assess strain variability.

The biotype of all strains was also studied by biochemical methods [1], and their capsular types were determined by

Received on 10 May 2008; revised 30 September 2008.

Address for correspondence: Dr. Wanderley Dias da Silveira. Telephone: (19) 3521-6268; E-mail: wds@unicamp.br.

The Brazilian Journal of Infectious Diseases

2008;12(5):430-437. (C) 2008 by The Brazilian Journal of Infectious Diseases and Contexto Publishing. All rights reserved.
PCR reaction using specific primers for each capsular type (af) [7]. All the results were compared to establish genetic identity among the different strains.

\section{Material and Methods}

Bacterial Strains and Media

The $45 \mathrm{H}$. influenzae strains used in this study were isolated from body fluids collected from patients attended at the Medical School Hospital of the Campinas (São Paulo) State University, from 1997 to 1998 (Table 1). These strains were cultivated under agitation (150 rpm), at $37^{\circ} \mathrm{C}$ in Brain Heart Infusion (BHI) broth supplemented with haemin $(10 \mu \mathrm{g} /$ $\mathrm{mL})$ and NAD (2 $\mu \mathrm{g} / \mathrm{mL})$ [9]. When necessary to grow the strains on solid medium, the BHI medium was supplemented with $1.5 \%$ agar. All strains were stored at $-80^{\circ} \mathrm{C}$ in $\mathrm{BHI}$ medium containing $15 \%$ glycerol.

\section{Strain Biotyping}

The strain biotyping media described by Kilian were used [1]. The strains were biotyped based on ornithine decarboxylase, urease, indol production, and D-xylose fermentation.

\section{Strain Capsular Typing}

Capsule types (a-f) were determined using primer pairs for each capsular type. Primer pairs and the PCR reactions were as described by Falla et al. [7].

\section{Genomic DNA Extraction}

Genomic bacterial DNA was extracted as described by Ausubel et al. [10]. The extracted DNA was resuspended in TE buffer plus $10 \mathrm{mg} / \mathrm{mL}$ of RNAse, and its integrity was determined using $0.7 \%$ agarose gels in TE buffer, as described by Sambrook et al. [11].

\section{PCRAmplification of $16 \mathrm{~S} r \mathrm{DNA}$}

The sequences of primers for the PCR 16S rDNA amplification were obtained from the Gene bank sequence 
accession number GI: 3551859 (16SForward: 5'GCTGACGAGTGGCGGACGGG-3'; 16SReverse: 5'GCTCGTTGCGGGACTTAACC-3'); 200 ng of genomic DNA was submitted to PCR amplification in a final volume of $50 \mu \mathrm{L}$ containing 10mM Tris-HCl (pH8.4); 50 mM KCl; $1.5 \mathrm{mM} \mathrm{MgCl}$; 50 pmol of each primer; $0.2 \mathrm{mM}$ of each deoxyribonucloeside triphosphate; 2.5 U of Taq DNA polymerase (Gibco BRL, Life Technologies). PCR reactions were run as follows: an initial denaturation $\left(95^{\circ} \mathrm{C}, 5 \mathrm{~min}\right)$, followed by 30 cycles of denaturation $\left(94^{\circ} \mathrm{C}, 1 \mathrm{~min}\right)$, annealing $\left(61^{\circ} \mathrm{C}, 1 \mathrm{~min}\right)$, and extension $\left(72^{\circ} \mathrm{C}, 2 \mathrm{~min}\right)$ with a final single extension $\left(72^{\circ} \mathrm{C}, 7\right.$ min). The size $(1,100 \mathrm{bp})$ of the expected fragment was visualized by electrophoresis in submersed agarose gels (1.5\%), using a $1 \mathrm{~kb}$ DNA marker (Gibco BRL, Life Tech), as a standard.

\section{RFLP of 16S rDNA with Enzymes BamHI and HaeIII}

For each strain, $500 \mathrm{ng}$ of the amplified 16S rDNA fragment (1,100 bp) was restricted either with BamHI or HaeIII enzymes, and the product separated using submersed agarose gel (1.5\%) electrophoresis. Visualization of the obtained fragments was accomplished as described by Sambrook et al. [11].

Non Radioactive-Labeling of the 16S rDNA Probe

The 16S rDNA fragment obtained after PCR amplification was labeled following the specifications described in the BioPrime TM DNA Labeling System instructions (Gibco BRL, Life Technologies).

\section{Southern Blotting}

For each strain, $5 \mu \mathrm{g}$ of the genomic DNA was digested with 20U of EcoRI (Gibco BRL, Life Technologies) and submitted to electrophoresis in a submersed agarose gel (0.7\%). The DNA was transferred to nylon membranes, as described by Sambrook et al. [11]. The 16S rDNA hibridization and membrane staining conditions followed the protocols described in the BluGene Nonradioactiove Nucleic Acid Detection System (Gibco BRL, Life Technologies).

\section{Data Analysis}

The data were analyzed with the POPGEN 32 package [12] and program UPGMA [13]. The presence of a given band was coded as 1 and its absence as 0 in a data matrix. Dissimilarity dendrograms were constructed for each case.

\section{Results}

The forty-five Haemophilus influenzae strains were isolated from November 1997 to June 1998 from patients attended at the Medical School Hospital of The Campinas State University (UNICAMP) and were classified either according to their site of isolation or the type of pathology with which they were associated (Table 1). Among these strains, $13 \%(n=6)$ were isolated from upper-respiratory-tract infections, $60 \%(n=27)$ from lower-respiratory-tract infections, $11 \%(n=5)$ from cerebral spinal fluid, $7 \%(n=3)$ from blood culture, $7 \%(n=3)$ from eye infections and $2 \%(n=1)$ from sinovial fluid (Table 1 ).

Biotyping demonstrated that $51 \%$ of the strains belonged to biotype I, $2 \%$ to biotype III, 31\% to biotype IV, $2 \%$ to biotype V, 7\% to biotype VI, and 7\% to biotype VIII. Biotypes II and VII were not found (Table 1).

Biotype and strain isolation origin were characteristically associated. Although the strains isolated from cystic fibrosis patients were mainly biotypes IV (47\%) and I (29.5\%), biotypes VI and VIII were also isolated in $6 \%$ and $17.5 \%$ of the cases, respectively. Invasive strains expressed biotype I (three strains isolated in meningitis cases and one strain isolated from blood culture), biotype IV (two strains isolated in meningitis cases and one strain from blood culture), and biotype V (one strain isolated from blood culture).

Capsular type characterization showed that most strains (89\%) were capsulated and nontypable, while only 2 and 9\% of the strains had capsule types a and b, respectively. Type-a strain was isolated from a pneumonia case, while type-b strains were isolated from blood culture (two strains) and cerebral spinal fluid (two strains).

Amplification of 16S $r$ DNA produced a DNA fragment of approximately 1,100bp. Digestion of this fragment with BamHI produced a restriction pattern with two types of fragments, one with a non-digested fragment of approximately 1,100bp and another with fragments of approximately 880 and 160bp. Digestion with HaeIII also produced two types of restriction patterns: one of approximately 785 and 235bp and another with approximately 480, 180, and 143bp fragments (fragments corresponding to differences in size not observable in the gels are not shown). Together, these data showed a high genetic similarity between strains, indicating only two (A-B) strain clusters (Figure 1). Cluster A comprised nearly all strains (93.3\%) and cluster B had only three strains. This analysis grouped most of the strains very close together, irrespective of biotype and capsular type, and showed very low variability between strains.

The construction of a molecular probe from a 1,100bp fragment of the $16 \mathrm{SrDNA}$ gene for hybridization with the restricted genomic DNA allowed identification of DNA fragments with molecular weights ranging from 195 to 19,212bp (data not shown). It resulted in eight (1-8) main strain clusters; however, they presented low dissimilarity between strains (0$25 \%$, Figure 2).

Clusters 1 and 4 contained five different strain clones, cluster 2 contained four clones, cluster 3 contained seven clones, clusters 5-8 contained either one or two strains each. Clusters 1 and 2, the ones with the lowest dissimilarity, contained all biotype VIII strains, most biotype IV strains (71.4\%), and only eight (33.3\%) biotype I strains, indicating a possible separation of strains with biotype IV.

Most strains (94.4\%) isolated from cystic fibrosis patients were grouped in clusters 1-3 with a maximum dissimilarity of approximately 15\%. However, the genomic structures of the most invasive strains, such as strain 40 (cerebral spinal fluid, 
Table 1. Isolation sites or body fluids from which the Haemophilus influenzae strains were isolated $(\mathrm{NT}=$ nontypable $H$. influenzae, $\mathrm{a}=$ serotype $\mathrm{a}, \mathrm{b}=$ serotype $\mathrm{b}$ ).

\begin{tabular}{|c|c|c|c|}
\hline Strains & Strain origin & Biotype & Serotype \\
\hline 1 & Cystic Fibrosis & I & NT \\
\hline 2 & Cystic Fibrosis & $\mathrm{I}$ & NT \\
\hline 3 & Cystic Fibrosis & VIII & NT \\
\hline 5 & Cystic Fibrosis & $\mathrm{IV}$ & NT \\
\hline 6 & Cystic Fibrosis & IV & NT \\
\hline 7 & Cystic Fibrosis & IV & NT \\
\hline 8 & Cystic Fibrosis & $\mathrm{I}$ & NT \\
\hline 9 & Cystic Fibrosis & IV & NT \\
\hline 10 & Cystic Fibrosis & IV & NT \\
\hline 11 & Cystic Fibrosis & IV & NT \\
\hline 12 & Cystic Fibrosis & IV & NT \\
\hline 13 & Cystic Fibrosis & $\mathrm{I}$ & NT \\
\hline 14 & Cystic Fibrosis & I & NT \\
\hline 15 & Cystic Fibrosis & VI & NT \\
\hline 16 & Cystic Fibrosis & IV & NT \\
\hline 17 & Cystic Fibrosis & VIII & NT \\
\hline 18 & Cystic Fibrosis & VIII & NT \\
\hline 19 & Cystic Fibrosis & $\mathrm{IV}$ & NT \\
\hline 20 & Bronchial Infection & VI & NT \\
\hline 21 & Amigdalytis & III & NT \\
\hline 22 & Amigdalytis & $\mathrm{I}$ & NT \\
\hline 23 & Bronchial-Alveolar Secretion & I & NT \\
\hline 24 & Bronchial-Alveolar Secretion & I & NT \\
\hline 26 & Ocular Secretion & I & NT \\
\hline 27 & Ocular Secretion & IV & NT \\
\hline 28 & Ocular Secretion & $\mathrm{I}$ & NT \\
\hline 29 & Sinus disease & I & NT \\
\hline 30 & Sinovial Liquid & VI & NT \\
\hline 31 & Sinusitis & $\mathrm{I}$ & NT \\
\hline 32 & Bronchial Secretion & I & NT \\
\hline 33 & Bronchial Secretion & IV & NT \\
\hline 34 & Bronchial Secretion & $\mathrm{I}$ & NT \\
\hline 35 & Sputum & I & NT \\
\hline 36 & Pneumonia case & I & NT \\
\hline 37 & Pneumonia case & I & NT \\
\hline 38 & Pneumonia case & I & A \\
\hline 39 & LCR - Meningitis & IV & NT \\
\hline 40 & LCR - Meningitis & I & NT \\
\hline 41 & LCR - Meningitis & I & NT \\
\hline 42 & LCR - Meningitis & $\mathrm{I}$ & B \\
\hline 43 & LCR - Meningitis & IV & B \\
\hline 44 & Pleural Liquid & I & NT \\
\hline 45 & Hemoculture - Meningitis & $\mathrm{V}$ & B \\
\hline 46 & Hemoculture - Meningitis & $\mathrm{I}$ & B \\
\hline 47 & Hemoculture - Meningitis & IV & NT \\
\hline
\end{tabular}


Figure 1. Dendrogram of dissimilarity obtained for Haemophilus influenzae strains using the RFLP of amplified 16S rDNA (bars = percentage of dissimilarity).

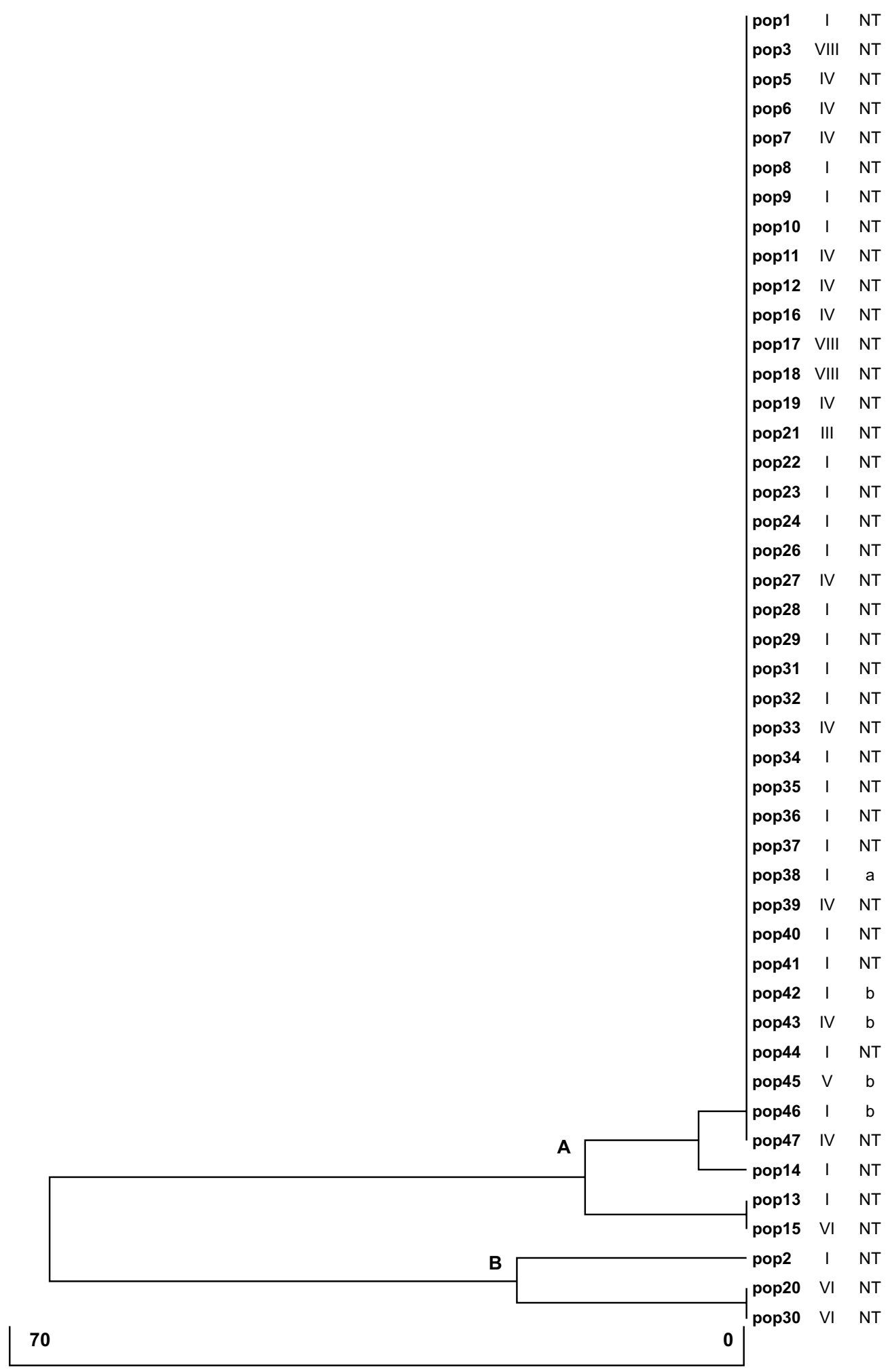


Figure 2. Dendrogram of dissimilarity obtained for Haemophilus influenzae strains using the amplified 16S rDNA region as a molecular probe (bars = percentage of dissimilarity).

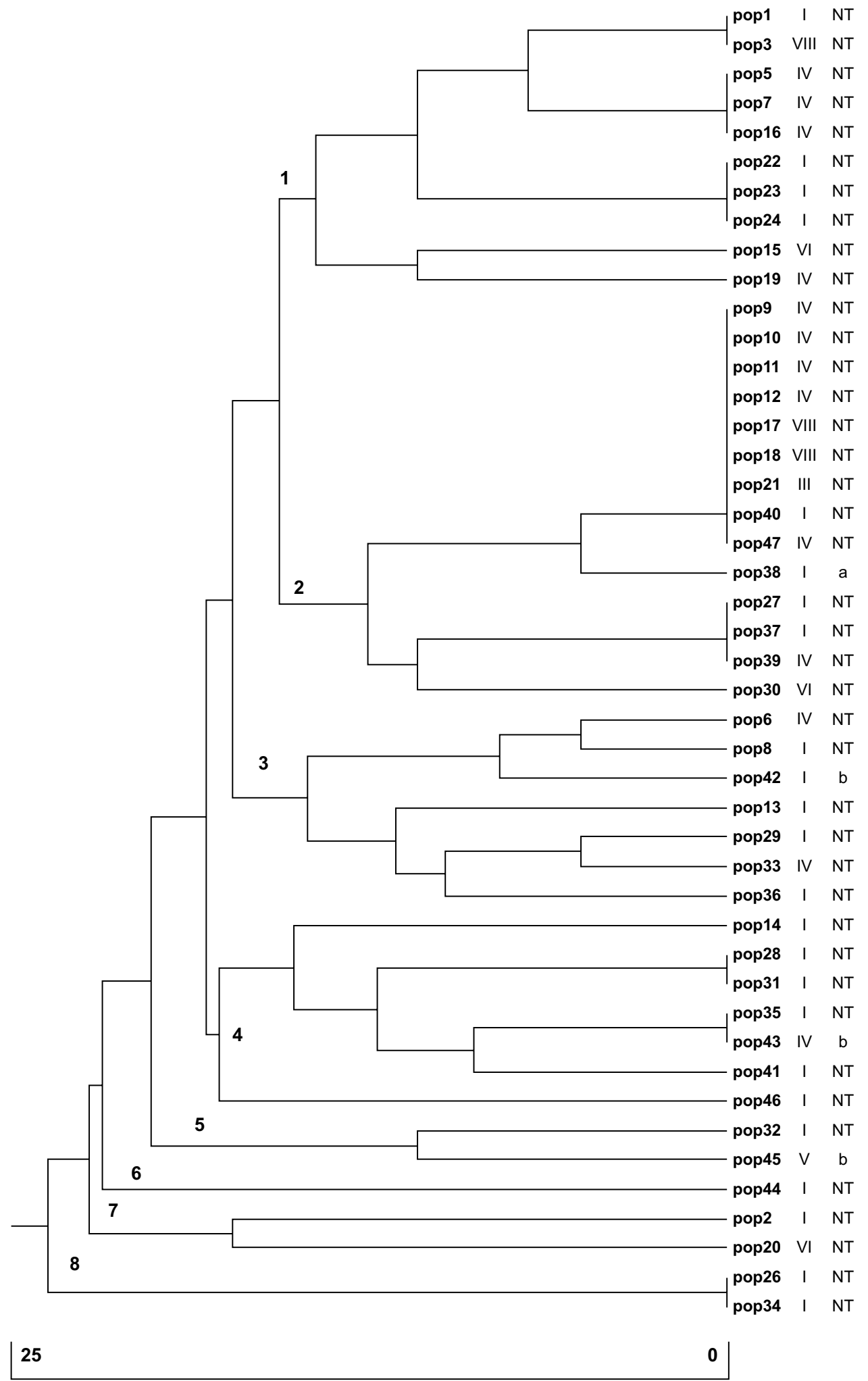

www.bjid.com.br 
Figure 3. Dendrogram of dissimilarity obtained for Haemophilus influenzae strains using $16 \mathrm{~S} r \mathrm{DNA} r \mathrm{DNA}$ region and the amplified 16S rDNA region as a molecular probe (bars = percentage of dissimilarity).

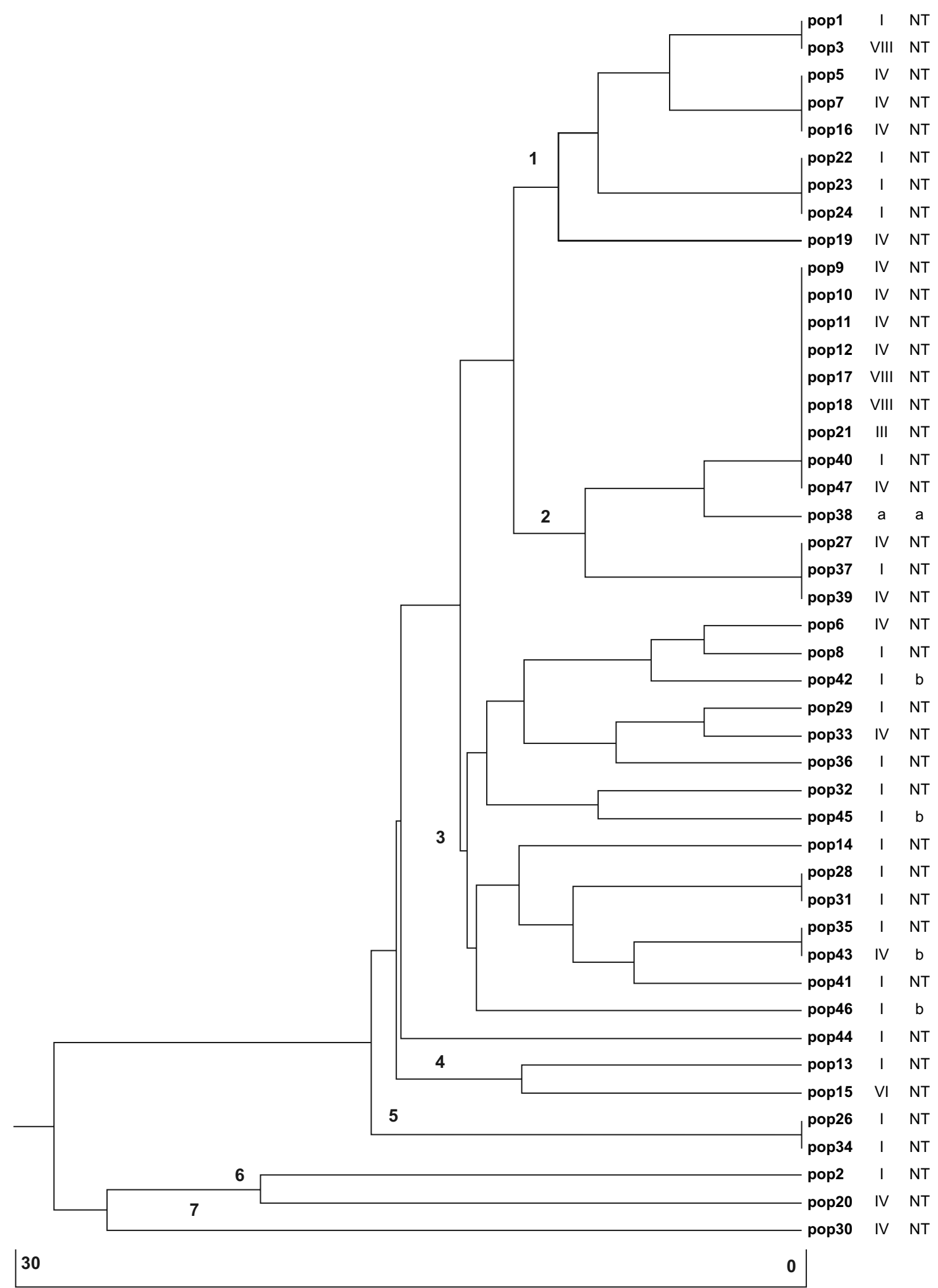

www.bjid.com.br 
biotype I, nontypable) and strain 47 (blood culture, biotype IV, nontypable) were either identical (strains 9-12, 17, and 18, for example) or very similar (strains 1 and 3, for example) to those strains isolated from cystic fibrosis patients. Likewise, strain 35 (sputum, biotype I and nontypable) and strain 43 (cerebral spinal fluid, biotype IV, capsular type b) (cluster 4) were identical strains by this approach. In addition, strains with theoretically the same pathogenic capacity were found in distinct clusters (strains 39 and 42, in clusters 2 and 3, respectively).

The combination of both techniques allowed us to construct a dendrogram with seven clusters (Figure 3), which was very similar to that constructed using the previous technique based on strain biotype and origin; but some strains, such as 15, 20, and 30 (all biotype VI) were reclustered in low genetic similarity clusters 4, 6, and 7, respectively.

\section{Discussion}

We used two technical variants of the same molecular assay (RFLP of 16S $r$ DNA cut with two different restriction enzymes and RFLP of genomic DNA with 16S $r$ DNA fragments as detected by a molecular $16 \mathrm{~S}$ probe) and their combination to examine clonal variability of clinical isolates of $H$. influenzae. Complementary biological characteristics, biotype, capsular type, and isolation site were determined for strain identification and characterization.

As $H$. influenzae is an important cause of human disease worldwide and serotype b (Hib) capsulated strains cause invasive infections, such as meningitis, septicemia, and septic arthritis, particularly in infants, many classification methodologies have been tried to better determine their virulence [4-8].

Haemophilus influenza is traditionally characterized by determination of biotype and capsular serotypes [14,15]. These methods are subject to phenotypic variations and do not provide information on the strain's clonal origin [16]. Biochemical discriminatory methods, such as outer membrane protein analysis, lipopolysaccharide profiling, multilocus enzyme electrophoresis, and several biomolecular techniques, including analysis of DNA restriction fragment length polymorphisms (RFLP), randomly amplified polymorphic DNA (RAPD), and amplification and enzyme restriction of the $r D N A$ gene, have been used in epidemiological and pathogenesis studies of $H$. influenzae. Amplification and enzyme restriction of the rDNA gene uses the ribosomal region as a typing and characterization target. RFLP analysis, using $r$ RNA (cloned $r$ DNA) as a probe, called ribotyping, has also been employed in the differentiation of several bacterial species isolates (Smith-Vaughn et al., 1995). Generally, genetic studies of $H$. influenzae use PCR-ribotyping with amplification of the $16 \mathrm{~s}$ RNA region, followed by enzyme restriction [17].

We found that only five strains (one type a and four type b) had a typable capsule. Epidemiological studies [17-19] have shown a high incidence of type b capsule among strains. Our results revealed more nontypable capsular strains, with good indication of isolation site. Most strains were non-invasive and isolated from cystic fibrosis and other respiratory tract clinical cases.

Most of the strains were biotypes I, IV, VI, VIII, III, and V, in decreasing order of frequency. These data are somewhat similar to what was found by Foxwell et al. [3] and Saito et al. [22], who reported that biotypes I, II, III, and IV were most frequent.

In addition, strain 45 expresses capsular type b and is biotype V. Till now, it was believed that invasive strains expressing this capsular type would belong only to biotypes I, II, or III [1].

Strains expressing capsular type b are considered to be the main ones responsible for meningitis in children up to five years of age [18-22]. We have also isolated nontypable $H$. influenzae strains (NTHi) in meningitis (strains 39; 40 and 41) and septicemia (strain 47) cases. The current practice of vaccination against type b $H$. influenzae during early childhood in Brazil may be selecting virulent strains that otherwise would have no epidemiological importance. A naturally competent bacteria capable of acquiring exogenous DNA from other strains is another factor to be considered in the exchange of virulence genes between strains of $H$. influenza (reviewed by Marrs et al. [23]), as it would favor the appearance of new pathogenic strains. In addition, differently from the results obtained by Saito et al. [19], we did not find strains expressing capsular types c, d, and f.

Among the techniques that we used to assess the clonal structure of this bacterial population, amplification of rDNA, followed by enzyme restriction showed a low discriminatory power among strains, since it yielded only two clusters. The discriminatory power increased when either 16S rDNA fragment was used as a molecular probe against total genomic DNA or with a combination of both analyses. We suggest that the use of this approach would give better results in epidemiological studies.

Independent of the method used to differentiate strains, non-invasive strains isolated from respiratory tract infections have a very close genetic identity with invasive pathogenic strains, which suggests that these two subgroups of bacteria have a common ancestor.

The similarity of the profiles of several strains found by these ribotyping techniques led to the conclusion that pathogenic and non-pathogenic $H$. influenzae strains could have similar or identical pathogenic mechanism genes. Different conditions would permit the expression of specific genes in specific microenvironments, thus regulating the expression of virulence factors according to host conditions. Again, exchange of DNA by lateral gene transfer and recombination, masking the prevalence of specific clones in the population of bacteria should also be considered, since $H$. influenzae is a naturally competent species, as previously reported [23,24]. Nevertheless, ribotyping allowed analysis of the genetic similarity of strains with phenotypic differences associated with the types of disease and the isolation sites. 
In conclusion, we found that: (i) characterization of $H$. influenzae strains using only the classic ribotyping technique is not enough to show the real variability between strains, (ii) a combination of techniques using different ribotyping techniques affords a higher discriminatory power, (iii) most of the strains were biotype I, (iv) most of the strains had an nontypable capsule, (v) one biotype V serotype b strain was first found responsible for meningitis in Brazil, (vi) nontypable strains were isolated from meningitis and septicemia cases, (vii) no strains expressing capsular types c, d, and f were detected, (viii) non-invasive strains isolated in respiratory tract infections have a very close genetic identity with invasive pathogenic strains, which indicates that pathogenic and non-pathogenic $H$. influenzae strains may have similar or identical pathogenic mechanism genes. Different conditions lead to the expression of specific genes in specific microenvironments, thus regulating the expression of virulence factors according to host conditions.

\section{Acknowledgement}

This work was supported by Grants no. 98/04612-9; no. 00/01864-9 and no. 00/01882-7 from Fundação de Amparo à Pesquisa do Estado de São Paulo-FAPESP and Grant no. 300121/90-3 from Conselho Nacional de Desenvolvimento Científico e Tecnológico-CNPq.

\section{References}

1. Kilian M. A taxonomic study of the genus Haemophilus, with the proposal of a new species. J Gen Microbiol 1976;93:9-62.

2. Turk D.C. Haemophilus influenzae type b resistant to both chloramphenicol and ampicillin in Britain. Br Med J (Clin Res Ed) 1982;284:1634.

3. Foxwell A.R., Kyd J.M., Cripps A.W. Nontypeable Haemophilus influenzae: pathogenesis and prevention. Microbiol Mol Biol Rev 1998;62:294-308.

4. Aparicio P., Roman F., Campos J. Epidemiological characterization of Haemophilus influenzae using molecular markers. Enferm Infecc Microbiol Clin 1996;14:227-32.

5. Smith-Vaughan H.C., Sriprakash K.S., Mathews J.D., Kemp D.J. Long PCR-ribotyping of nontypeable Haemophilus influenzae. J Clin Microbiol 1995;33:1192-5.

6. Moller L.V., Grasselier H., Dankert J., van Alphen L. Variation in metabolic enzyme activity of persistent Haemophilus influenzae in respiratory tracts of patients with cystic fibrosis. J Clin Microbiol 1996;34:1926-9.

7. Falla T.J., Crook D.W., Brophy L.N., et al. PCR for capsular typing of Haemophilus influenzae. J Clin Microbiol 1994;32:2382-6.
8. Gonin P., Lorange M., Delage G. Performance of a multiplex PCR for the determination of Haemophilus influenzae capsular types in the clinical microbiology laboratory. Diagn Microbiol Infect Dis 2000;37:1-4.

9. Musser J.M., Granoff D.M., Pattison P.E., Selander R.K. A population genetic framework for the study of invasive diseases caused by serotype b strains of Haemophilus influenzae. Proc Natl Acad Sci U S A 1985;82:5078-82.

10. Ausubel F.M., Brent, R., Kingston R.E., et al. Current Protocols in Molecular Biology Greene Publishing Associates, Brooklin, 1988.

11. Sambrook J., Fritsch, E.F., Maniatis T. Molecular Cloning - A Laboratory Manual Cold Spring Harbor Laboratory Press, USA, 1989.

12. Yeh F.C., Boyle F.T., Rongcai Y., et al. POPGENE 1.31 version: Microsoft Window-based Freeware for Population Genetic Analysis.: Online.Universiry of Alberta, 1999.

13. Nei M. The theory of genetic distance and evolution of human races. Jinrui Idengaku Zasshi 1978;23:341-69.

14. Moxon E.R. The molecular basis of Haemophilus influenzae virulence. J R Coll Physicians Lond 1985;19:174-8.

15. Moxon R., Bayliss C., Hood D. Bacterial contingency loci: the role of simple sequence DNA repeats in bacterial adaptation. Annu Rev Genet 2006;40:307-33.

16. Gomez-De-Leon P., Santos J.I., Caballero J., et al. Genomic variability of Haemophilus influenzae isolated from Mexican children determined by using enterobacterial repetitive intergenic consensus sequences and PCR. J Clin Microbiol 2000;38:2504-11.

17. Mitsuda T., Kuroki H., Ishikawa N., et al. Molecular epidemiological study of Haemophilus influenzae serotype b strains obtained from children with meningitis in Japan. J Clin Microbiol 1999;37:2548-52.

18. Moor P.E., Collignon P.C., Gilbert G.L. Pulsed-field gel electrophoresis used to investigate genetic diversity of Haemophilus influenzae type b isolates in Australia shows differences between Aboriginal and non-Aboriginal isolates. J Clin Microbiol 1999;37:1524-31.

19. Saito M., Umeda A., Yoshida S. Subtyping of Haemophilus influenzae strains by pulsed-field gel electrophoresis. J Clin Microbiol 1999;37:2142-7.

20. Moxon E.R., Deich R.A., Connelly C. Cloning of chromosomal DNA from Haemophilus influenzae. Its use for studying the expression of type b capsule and virulence. J Clin Invest 1984;73:298-306.

21. Moxon E.R., Kroll J.S. Type b capsular polysaccharide as a virulence factor of Haemophilus influenzae. Vaccine 1988; $6: 113-5$.

22. Saito M., Okada K., Takemori K., Yoshida S.I. Clonal spread of an invasive strain of Haemophilus influenzae type b among nursery contacts accompanied by a high carriage rate of non-diseaseassociated strains. J Med Microbiol 2000;49:845-7.

23. Marrs C.F., Krasan G.P., McCrea K.W., et al. Haemophilus influenzae - human specific bacteria. Front Biosci 2001;6:41-60.

24. Clemans D.L., Marrs C.F., Bauer R.J., et al. Analysis of pilus adhesins from Haemophilus influenzae biotype IV strains. Infect Immun 2001;69:7010-9. 